\title{
Oxytocics and other Drugs in Prevention of Post-partum Haemorrhage
}

Postpartum haemorrhage (PPH) is one of the major causes of maternal mortality and morbidity globally. PPH complicates $11 \%$ of deliveries worldwide and is annually responsible for $1,32,000$ maternal deaths. ${ }^{1}$ In developing countries, mortality from $\mathrm{PPH}$ remains high $^{2}$ and PPH accounting for $30 \%$ of maternal death ${ }^{3}$, while in Bangladesh it is $31 \% .{ }^{4}$ All pregnant women are at risk of complications during the third stage of labour. ${ }^{5}$

Uterine atony is responsible for the most of $\mathrm{PPH}$ cases and can be managed by uterine massage in conjunction with oxytocin, prostaglandins and ergot alkaloids. The prophylactic use of oxytocin reduces the rate of $\mathrm{PPH}$ by $40 \%{ }^{6}$

Oxytocics are the drugs of varying chemical nature that have the power to stimulate the contraction of uterine muscle. They are also known as uterotonics or ecbolics. The introduction of oxytocic drugs for the treatment of PPH has been regarded as one of the enduring achievements of modern medicine. The oxytocics are of following types:

- Posterior pituitary hormones-oxytocin, carbetocin.

- Ergot alkaloid (Ergometrin, methylergotamin)

- Prostaglandins (PGE, PGF2, Mosoprostol)

- Miscellaneous (quinine, emetine, alcohol, ethacridine)

Oxytocin is an effective first line treatment for postpartum haemorrhage. Oxytocin $10 \mathrm{IU}$ should be injected IM or $20 \mathrm{IU}$ in $1 \mathrm{~L}$ of saline to be infused at a rate of $250 \mathrm{ml}$ per hour. As much as $500 \mathrm{ml}$ can be infused over 10 minutes without complications. The active management of third stage of labour include use of oxytocin 10 IU by IM soon after delivery of anterior shoulder of delivery of the baby by controlled cord traction and uterine massage to reduce postpartum blood loss. Oxytocin has some limitations like shorter half life ${ }^{7}$, less contraction time and more side effects like fluid overload, convulsion, arrhythmia and pulmonary oedema. In addition, the ergot alkaloids cannot be used in $10-15 \%$ of women who have gestational hypertension. ${ }^{8}$ Further, oxytocin and ergot preparation require protection against light to preserve its effectiveness and stability. ${ }^{9}$ Oxytocics should be stored in refrigerator $\left(2-8^{\circ} \mathrm{C}\right)$ and away from light. In our country, cold chain is not properly maintained for oxytocin and may cause reduction in its effectiveness and stability. As a result treatment failure can occur. Till now it is recommended that oxytocin should be used as uterotonic agent either in the form of intramuscular injection or intravenous infusion.

Ergot alkaloids (Ergotamine derivative) are used to increase the strength of uterine contraction to reduce postpartum bleeding and promote postpartum involution. Because ergot associated contraction are tonic rather than rhythmic these agents cannot be used in labour. Prophylactic IM or IV injection of ergot alkaloids may be effective in reducing blood loss and $\mathrm{PPH}$. It may also decrease the use of therapeutic uterotonics but adverse effects may include elevated blood pressure and pain after birth requiring analgesia. Other adverse effects are vomiting, nausea, headache or eclamptic fits. There is also lack of evidence ergot alkaloids on severe PPH and retained placenta or manual removal of placenta. There is also a lack of evidence on the oral route of administration of ergot alkaloids. Methylergonovine (Methergine) and ergotamine are alkaloids causes generalized smooth muscle contraction in which both the upper and lower uterine segment contracts titanically. Usual dose of Methylergonovine, $0.2 \mathrm{mg}$ IM and repeated dose at an interval of 2-4 hours if needed.

Postaglandins enhance uterine contractility and cause vasoconstriction. Most commonly used prostaglandins is 15-methyl prostaglandin F2 $\alpha$ or carboprost (Hemabate). Carboprost can be administered IM or intramyometrially in a dose of 0.25 mg may be repeated every 15 minutes for a total close of $2 \mathrm{mg}$. In case of asthma or hypertension, carboprost should be used carefully. The side effects 
are nausea vomiting, diarrhoea, hypertension, headache, flashing and pyrexia. Another prostaglandin is misoprostol which also increase the uterine contractility and reduces the postpartum haemorrhage effectively. It can be administered sublingually, orally, vaginally and rectally. Doses range from 200 to $1000 \mathrm{mcg}$; the dose recommended by FIGO is $800 \mathrm{mcg}$ sublingually. Higher doses are associated with shivering, pyrexia and diarrhoea but this agent is inexpensive heat and light stable. ${ }^{10,11,12}$

Carbetocin is a long-acting synthetic analogue of oxytocin with agonist properties. Carbetocin has prolonged duration of action (approximately 1hour) which ensures more contraction time and less adverse effect. ${ }^{13,14}$ The clinical and pharmacological properties of carbetocin are similar to those of naturally occurring oxytocin. Carbetocin binds to oxytocin receptors present on the smooth musculature of the uterus, resulting in rhythmic contractions of the uterus, increased frequency of existing contractions and increased uterine tone. ${ }^{15} \mathrm{~A}$ single dose of carbetocin has been hypothesis to act up to 16 hours in comparison to intravenous oxytocin infusion regarding the increase in uterine tone and the reduction of the risk of $\mathrm{PPH}$ in caesarean section. ${ }^{8}$

Tranexamic acid (TXA), an antifibrinolytic agent was identified as a promising drug in reducing $\mathrm{PPH}$. The largest trial of tranexamic acid for $\mathrm{PPH}$ treatment to date, the World Maternal Antifibrinilytic (WOMAN) trial was published online in April 2017. ${ }^{16}$ The WOMAN trial was a randomized, double-blind, placebocontrolled trial randomizing woman with a clinical diagnosis of PPH (regardless of mode of delivery) to a regimen of intravenous TXA or identical placebo. More than 20,000 women were recruited in this study. This study showed that early use (within 3 hours) of TXA reduces maternal death due to PPH in women and that early treatment appears to optimize benefit.

\section{Prof. Sameena Chowdhury}

Prof. of Obs \& Gyaen.

President Elect-OGSB

Email: dr.sameenachowdhury@gmail.com

Mobile: 01715055175

\section{References:}

1. Carroli G, Cuesta C, Abalos E, Gulmezoglu AM. Epidemiology of postpartum haemorrhage: a systematic review. Best practice \& research Clinical obstetrics \& gynaecology. 2008 Dec 1;22(6):999-1012.

2. American Academy of Family Practitioners (AAFP). Advanced Life Support in Obstetrics. Syllabus Updates.Downloaded 21/05/2008 from www.aafp.org/online/en/ home/cme/ aafpcourses/clinicalcourses/also/syllabus. ht ml\#Parsys0003, 2008

3. Derman R, Kodkany BS, Goudar SS, Geller SE, Naik VA, Bellad MB, Patted SS, Patel A, Edlavitch SA, Hartwell T, Chakraborty H, Moss N.Oral misoprostol in preventing postpartum haemorrhage in resource-poor communities: a randomised controlled trial. Lancet 2006; 368:1248-53.

4. National Institute of Population Research and Training (NIPORT), MEASURE Evaluation, UNC-CH, USA, ICDDR, B., 2011

5. Smith JR. Management of Third Stage of Labor: January 6, 2012

6. Nordstrom L, Fogelstam K, Fricalman G et at. Routine oxytocin in the third stage of labour: a placebo controlled trial. BrJ obstet Gynaecol. 1997; 104: 781-6.

7. Oyelese Y, Scorza WE, Mastrolia R, Smulian JC .Post- partum hemorrhage. Obstet Gynecol Clin N Am 2007; 34(3):421-441.

8. G Larciprete, C Montagnoli, M Frigo, V Panetta $\mathrm{J}$, Prenat et al Carbetocin versus oxytocin in caesarean section with high risk of post-partum haemorrhage Med. 2013 Jan-Mar; 7(1): 12-18.

9. Werner R. Prevention of postpartum haemorrhage with the oxytocin analogue carbetocin. European Journal of Obstetrics and Gynecology and Reproductive Biology; 2009; 147 (1): 15-20.

10. Mousa HA, Alfirevic Z. Treatment of primary post partum haemorrhage cochrano. Data base8 yst Rev. 2003; (1);CD003249.

11. Chong YS, Chua S, Shen L, Arulkumaran S, Does the route of administration of misoprostol given by different moutes after vaginal delivery. Ewe J Obstet Gynaecol Reprod Biol. 2004; 113: 191-8 
12. Prophylactic use of ergot alkaloids in the third stage of labour. Liabsuetrakul T, et al. cochranc Data base syst Rev. 2018.

13. Tharakan T, Jha J Randomized double blind prospective trial of active management of the third stage of labor. Arch Med Sci 2008; 4(1):7982.

14. Sergio RO, RPAguado et al. Carbetocin versus oxytocin for prevention of postpartum haemorrhage: a randomized controlled trial. Published Online February 26, 2014 School of Clinical and Experimental Medicine, University of Birmingham, UK
15. Werner R. Prevention of postpartum haemorrhage with the oxytocin analogue carbetocin. European Journal of Obstetrics and Gynecology and Reproductive Biology; 2009; 147 (1): 15-20.

16. Shakur, H., Roberts, I., Fawole, B., Chaudhri, R., El-Sheikh, M., Akintan, A., ... \& Etuk, S. (2017). Effect of early tranexamic acid administration on mortality, hysterectomy, and other morbidities in women with post-partum haemorrhage (WOMAN): an international, randomised, double-blind, placebo-controlled trial. The Lancet, 389(10084), 2105-2116. 